\title{
Ethylene-Nitric Oxide Interplay During Selenium-induced Lateral Root Emergence in Arabidopsis
}

\author{
Gábor Feigl ${ }^{1}$. Edit Horváth ${ }^{1} \cdot$ Árpád Molnár ${ }^{1} \cdot$ Dóra Oláh $^{1} \cdot$ Péter Poór $^{1} \cdot$ Zsuzsanna Kolbert $^{1}$ (I)
}

Received: 28 November 2018 / Accepted: 12 February 2019 / Published online: 28 March 2019

(c) The Author(s) 2019

\begin{abstract}
Selenium (Se) results in primary root shortening and the concomitant induction of lateral roots (LRs) (stress-induced morphogenic response, SIMR). Both ethylene (ET) and nitric oxide (NO) are gasotransmitters interacting with each other during plant growth regulation; however, their involvement and interplay in LR growth have not been examined so far. This study investigates the effect of Se on ET and NO levels and interaction in wild-type (WT) and ET insensitive etrl-1 Arabidopsis. In WT, Se at $15 \mu \mathrm{M}$ concentration triggered LR emergence $\left(\mathrm{LR}_{\mathrm{em}}\right)$ and slight ET level elevation but in etrl-1 Se-induced LR inhibition was accompanied by four-fold ET level increase which can be associated with the increased expression of ACS2 and ACS8. Treatment with ACC + Se decreased $\mathrm{LR}_{\mathrm{em}}$ and NO level in WT, whereas AVG + Se in the etrl-1 plants resulted in enhanced $\mathrm{LR}_{\mathrm{em}}$ and increased NO level indicating that ET may inhibit both NO formation and LR emergence in Se-stressed Arabidopsis. The expression of NO-associated genes (NR1, NR2, GSNOR1, GLB1, GLB2), however, did not correlate with NO levels. Application of GSNO together with Se resulted in enhanced LR outgrowth both in WT and in etrl-1, whereas this effect could be reversed by a NO scavenger which indicates the positive regulatory role of NO during LR emergence. Moreover, GSNO has a clear inhibitory and cPTIO has an inducing effect on ET levels. These data indicate for the first time that the antagonistic interplay between ET and NO regulates the emergence of lateral roots in Arabidopsis under Se stress.
\end{abstract}

Keywords Ethylene $\cdot$ Lateral root outgrowth $\cdot$ Nitric oxide $\cdot$ Selenite

\section{Introduction}

Selenium (Se) is a naturally occurring non-metal element which is taken up by plants as selenate or selenite (Sors et al. 2005). Due to the chemical similarities with sulphur (S), land plants metabolize Se via S assimilation pathways (Sors et al. 2005). Excess Se negatively impacts plants and causes general symptoms including chlorosis, withering, and stunted shoot and root growth. There are several known reasons for Se phytotoxicity like malformation of selenoproteins, impaired primary metabolism, oxidative and nitrosative stress and hormonal imbalance (Kolbert et al. 2016).

Electronic supplementary material The online version of this article (https://doi.org/10.1007/s00344-019-09950-9) contains supplementary material, which is available to authorized users.

Zsuzsanna Kolbert

kolzsu@bio.u-szeged.hu

1 Department of Plant Biology, University of Szeged, Szeged, Hungary
At certain concentrations, Se was shown to induce a mixed growth response (stress-induced morphogenic response, SIMR, Potters et al. 2007) during which the primary root (PR) elongation is inhibited and the lateral root (LR) growth is induced (Kolbert 2016).

Of plant hormones, auxin, cytokinins, ethylene (ET) and jasmonic acid (JA) have been related to Se stress in previous studies (Van Hoewyk et al. 2008; Tamaoki et al. 2008; Lehotai et al. 2012, 2016). Transcriptomic analyses revealed that Se upregulates ET- and JA-associated genes in Arabidopsis and mutants defective in ET or JA signaling exhibited Se sensitivity relative to the wild-type (Van Hoewyk et al. 2008). In our previous work, we determined that $\mathrm{Se}$ increases ET levels and we assumed that ET might positively regulate Se tolerance (Lehotai et al. 2012). These suggest a relevant role for especially ET in Se tolerance. In addition to its stress hormone role, ET also regulates the initiation of laterals in the pericycle as well as LR outgrowth and elongation (Ivanchenko et al. 2008; Negi et al. 2008).

Depending on the plant species, growth conditions and concentrations, Se is able to increase or decrease the level 
of another gasotransmitter, nitric oxide (NO) (Lehotai et al. 2012, 2016; Chen et al. 2014; Molnár et al. 2018a, b; Kolbert et al. 2018). At low concentration, NO is believed to act as a signal regulating stress responses or growth often being associated with hormonal signalling pathways. There are several reports indicating NO-ET interplay during diverse growth responses and the nature of their interaction proved to be mutually negative (reviewed by Freschi 2013). However, we have no knowledge about ET and NO being involved in Seinfluenced LR development and their possible interaction is also unclear. Therefore, we aimed to examine the supposed contribution and the putative interplay of ET and NO to the regulation of Se-modified LR growth in Arabidopsis.

\section{Materials and Methods}

\section{Plant Material and Growth Conditions}

Seven-day-old wild-type (Col-0, WT), etrl-1 mutant (AT1G66340, NASC ID: N237; Chang et al. 1993) and ACS8::GUS/GFP (NASC ID: N31385; Tsuchisaka and Theologis 2004) Arabidopsis thaliana L. seedlings were used. The seeds were surface sterilized with $70 \%$ (v/v) ethanol and 5\% (v/v) sodium hypochlorite and transferred to halfstrength Murashige and Skoog medium (1\% (w/v) sucrose and $0.8 \%(\mathrm{w} / \mathrm{v})$ agar) supplemented with 0 (control), 5, 10, 15 or $20 \mu \mathrm{M}$ sodium selenite $\left(\mathrm{Na}_{2} \mathrm{SeO}_{3}\right)$. For root morphology observations and staining methods, 25-30 plants per plate, for PCR method approx. 60 plants per plate, while for ET quantification 120 plants per plate were cultivated. The Petri dishes were kept vertically in a greenhouse at a photo flux density of $150 \mu \mathrm{mol} \mathrm{m}{ }^{-2} \mathrm{~s}^{-1}$ (12/12 day/night period) at a relative humidity of $55-60 \%$ and $25 \pm 2{ }^{\circ} \mathrm{C}$ for 7 days.

\section{Chemicals and Treatments}

Endogenous ET levels were increased by the addition of 1-aminocyclopropanecarboxylic acid (ACC, $5 \mathrm{nM}$ ) and ET synthesis was inhibited by aminoethoxyvinyl glycine (AVG, $1.5 \mu \mathrm{M})$. As a NO donor, $250 \mu \mathrm{M}$ S-nitrosoglutathione (GSNO) and as a NO scavenger $800 \mu \mathrm{M}$ 2-(4-carboxyphenyl)4,4,5,5-tetramethylimidazoline-1-oxyl-3-oxide (cPTIO) were used. Stock solutions of ACC or AVG (in water) were added through sterile filters to the medium cooled to $50{ }^{\circ} \mathrm{C}$ (7-daylong treatments). Stock solutions of GSNO or cPTIO (in DMSO) were added on the surface of the media containing the root system of 4-day-old seedlings through sterile filters (3-day-long treatments). The effective concentrations were chosen in pilot experiments and water or DMSO was added to the medium as controls. Chemicals were purchased from Sigma-Aldrich (Merck, St. Louis, MO, USA).

\section{Root Morphological Observations}

Lateral roots within the primary root (smaller than stage VII) were considered as lateral root primordia $\left(\mathrm{LR}_{\text {prim }}\right)$, whereas visible laterals which have already grown outside the PR were considered as emerged LRs $\left(\mathrm{LR}_{\mathrm{em}}\right.$, larger than stage VII, Fig S1, Malamy and Benfey 1997). In each experiment, the root systems of at least 20 plants were observed under a Zeiss Axiovert 200M microscope (Carl Zeiss Inc., Jena, Germany).

\section{Gas Chromatographic Measurement of ET Production}

Arabidopsis seedlings (500 mg, 350-360 seedlings) were incubated in $0.5 \mathrm{ml}$ distilled water for $60 \mathrm{~min}$ in gas-tight flasks fitted with a rubber serum stopper under darkness. A sample $(2.5 \mathrm{ml})$ of the gas was removed from the flasks with a gas-tight syringe and injected to a Hewlett-Packard 5890 Series II gas chromatograph equipped with a flame ionization detector (Poór et al. 2015). Five parallel samples per experiment were measured and the experiment was repeated twice.

\section{GUS Histochemical Staining}

In the GUS-tagged Arabidopsis line (ACS8::GUS/GFP), $\beta$-glucuronidase activity was visualized according to Zhong et al. (2014). In each experiment, at least 10 seedlings were stained and representative images were selected.

\section{Fluorescence Microscopy}

Nitric oxide levels in Arabidopsis root tips were analysed by 4-amino-5-methylamino-2',7'-difluorofluorescein diacetate (DAF-FM DA) according to Feigl et al. (2013). In each experiment, at least 10 seedlings were stained and representative images were selected.

\section{qRT-PCR Analysis of NO- and ET-Associated Genes}

The expression rate of NO- and ET-associated genes in Arabidopsis thaliana was determined by quantitative realtime reverse transcription-PCR (RT-qPCR). RNA was purified from $90 \mathrm{mg}$ plant material by using a NucleoSpin RNA Plant mini spin kit (Macherey-Nagel) according to the manufacturer's instruction. An additional DNase digestion was applied (Thermo Scientific), and cDNA was synthetized using RevertAid reverse transcriptase (Thermo Scientific). Primers were designed for the selected coding sequences using the Primer3 software; the primers used for RT-qPCR are listed in Table S2. The expression rate of the selected 
genes was monitored by quantitative real-time PCR (qRTPCR, Jena Instruments) using SYBR Green PCR Master Mix (Thermo Scientific) as described by Gallé et al. (2009). Data analysis was performed using qPCRsoft3.2 software (Jena instruments). Data were normalized to the transcript levels of the control samples; actin2 (At3g18780) and GAPDH2 (Atlg 13440) were used as internal controls (Papdi et al. 2008). Each reaction was carried out in two replicates using cDNA synthesized from independently extracted RNAs and the experiments were repeated two times.

\section{Statistical Analysis}

All experiments were carried out at least two times. Results are expressed as mean \pm SE. Multiple comparison analyses were performed with SigmaStat 12 software using analysis of variance (ANOVA, $P<0.05$ ) and Duncan's test.

\section{Results and Discussion}

Selenite was applied at different concentrations and the number of lateral root primordia and emerged lateral roots were counted in wild-type Arabidopsis. The data are presented as Fig S2 and Table S1. The $5 \mu \mathrm{M}$ concentration had no effect on LR numbers, and $10 \mu \mathrm{M}$ Se significantly increased only the number of emerged LRs which resulted in unmodified total LR number and a decreased LR primordia:emerged $\mathrm{LR}$ ratio $\left(\mathrm{LR}_{\text {prim }}: \mathrm{LR}_{\mathrm{em}}\right)$. The effect of $15 \mu \mathrm{M}$ Se proved to be interesting as it remarkably reduced LR initiation (40\% reduction) while it induced LR outgrowth (125\% induction) resulting in decreased total LR number and a lower $\mathrm{LR}_{\text {prim }}: \mathrm{LR}_{\mathrm{em}}$ ratio ( $\sim 50 \%$ decrease $)$ compared to control. For further examination $15 \mu \mathrm{M}$ selenite was chosen. In Se-treated plants, the number of visible (emerged) laterals increased, which led to a more branched root system. This was accompanied by shortening of the primary root (data not shown) which can be considered as a symptom of stressinduced morphogenic response.

Lateral root emergence is known to be regulated by ET (Negi et al. 2008; Ivanchenko et al. 2008), thus we suspected that ET signalling is involved also in Se-induced LR outgrowth. Therefore, we compared the LR numbers of WT and etr $1-1$ in case of $15 \mu \mathrm{M}$ selenite treatment (Fig. 1a). During control circumstances, etrl- 1 can be characterized by the higher number of LRs and lower $\mathrm{LR}_{\text {prim }}: \mathrm{LR}_{\mathrm{em}}$ ratio compared to the WT (Table S1). The number of LR primordia was WT-like but the emergence was intensified in control etrl-1 (Negi et al. 2008, Fig. 1a). Although Se intensified LR outgrowth of the WT (Fig S2 and Fig. 1a), in etrl-1 the number of emerged LRs were not increased by Se, instead a significant reduction was observed in the number of $L_{\text {prim }}$, number of $\mathrm{LR}_{\mathrm{em}}$, total $\mathrm{LR}$ number and $\mathrm{LR}_{\mathrm{prim}}: \mathrm{LR}_{\mathrm{em}}$ ratio
(Table S1 and Fig. 1a). These results indicate that LR initiation and emergence of ET insensitive etrl-1 are more sensitive to Se compared to the wild-type. Furthermore, Se was not able to accelerate LR emergence in the absence of ET resistant (ETR) signalling, which reflects to the involvement of ETR-dependent ET signalling in Se-induced LR outgrowth.

Despite the differences in their control root system (Fig. 1a), the ET levels were similar in the wild-type and in etr1-1 (Fig. 1b). Selenium exerted different degrees of effect on ET levels in the plant lines, since Se caused a two-fold elevation in ET levels (measured in whole seedlings, Fig. 1b and detected in ACS8::GUS/GFP roots, Fig. 1c) in the WT. Although, in etrl-1 seedlings, Se resulted in a significant, four-fold ET level increase (Fig. 1b).

Based on these, it was supposed that the high Se-induced ET levels may be responsible for the inhibition of LR outgrowth in etrl-1. The effects of ACC and AVG treatments on ET levels were determined by GUS staining in differentially developed LRs and PR tips of ACS8::GUS/GFP (Fig. 1c). The ACC treatment increased the ACS8::GUS signal, whereas in AVG-treated roots, the activity of ACS8::GUS decreased (Fig. 1c) indicating that the applied concentrations of ACC and AVG could effectively modulate ET levels in Arabidopsis roots. As shown in Fig. 1d, ACC applied together with Se inhibited LR outgrowth in WT plants, which suggests that increased ET (ACC) has a negative impact on Se-induced LR outgrowth (Fig. 1d). Moreover, the reduction of high ET levels of Se-stressed etrl-1 led to the induction of LR outgrowth (Fig. 1e) which clearly indicates the inhibitory effect of ET in LR emergence as the effect of Se. Regarding the mechanism of ET action, an interplay between ET and auxin can possibly lead to decreased LR emergence in the presence of Se. In response to Se-increased ET levels, auxin transport may be enhanced through the root which limits the auxin that remains in the root locally to stimulate lateral root outgrowth (Negi et al. 2008).

We further investigated the Se-induced alterations in the expression of selected ET synthesis and signalling genes (ACS2, ACS6, ACS8, ACO4, ERS1, ERS2, CTR1, Fig. 2). All the examined ACS genes are expressed in the roots (Dugardeyn et al. 2008). Without Se application, 1-aminocyclopropane-1-carboxylic acid (ACC) synthase (ACS2 and ACS8) genes were upregulated in etr 1-1 compared to the WT, whereas ACC oxidase (ACO4) and ethylene response sensor (ERS1 and $E R S 2)$ genes were downregulated. In WT, Se reduced ACS2 and ACS6 expression; however, of the ET signal components only the expression of ERS2 proved to be Se responsive. In etr 1-1, Se highly upregulated ACS2 and ACS 8 genes and the expressions of ET signalling genes were not influenced by Se. Similarly, the expression of ACS2 was induced by cadmium and proved to have a key role in ET synthesis in Arabidopsis 

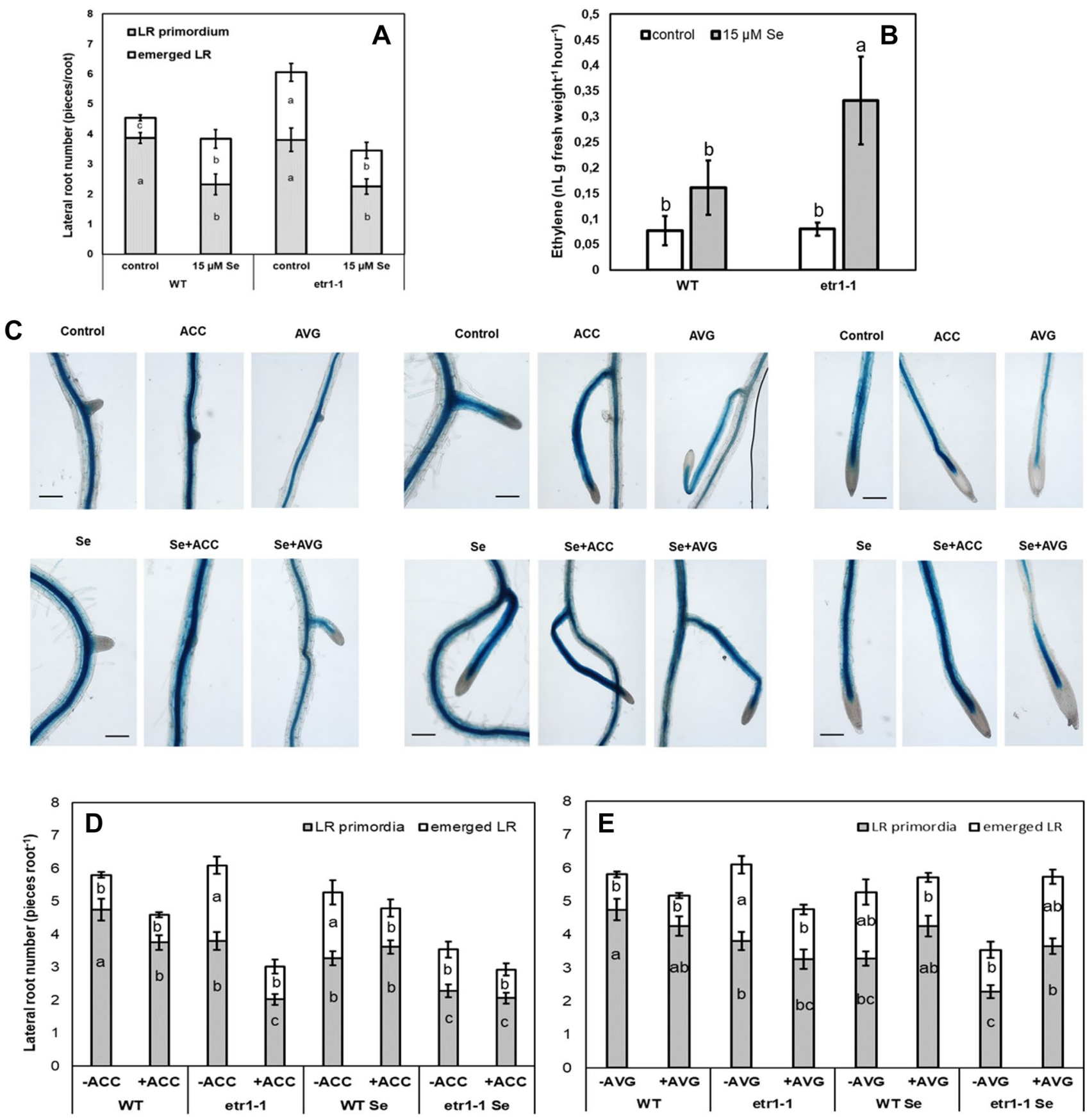

Fig. 1 a Number of lateral root (LR) primordia and emerged LRs in 7-day-old wild-type (WT) and etr1-1 Arabidopsis grown in the presence or absence of $15 \mu \mathrm{M}$ selenite. b Ethylene concentration $(\mathrm{nL} \mathrm{g}$ fresh weight ${ }^{-1} \mathrm{~h}^{-1}$ ) in 7-day-old wild-type and etrl-1 seedlings treated with 0 or $15 \mu \mathrm{M}$ selenite. c Primary roots and differentially developed LRs of X-Gluc-stained ACS8::GUS/GFP Arabidopsis grown on agar medium supplemented with 0 or $15 \mu \mathrm{M}$ selenite with or without $5 \mathrm{nM}$ ACC and $1.5 \mu \mathrm{M}$ AVG. Bars $=500 \mu \mathrm{m}$. d Number

(Schellingen et al. 2014). The results show that Se differentially regulates $A C S$ gene expression in the WT and in etr1-1, which may contribute to the observed differences in ET levels evolved by Se (Fig. 1b). At the same time, in

of LR primordia and emerged LRs in 7-day-old wild-type and etr1-1 Arabidopsis grown in the presence or absence of $15 \mu \mathrm{M}$ selenite with or without $5 \mathrm{nM}$ ACC. e Number of LR primordia and emerged LRs in 7-day-old wild-type and etr1-1 Arabidopsis grown in the presence or absence of $15 \mu \mathrm{M}$ selenite with or without $1.5 \mu \mathrm{M}$ AVG. Different letters indicate significant differences according to Duncan's test $(n=20, P \leq 0.05)$

control etr $1-1$ plants, ACS2 and ACS 8 genes were highly expressed similarly to the results of Peng et al. (2005). The level of ET in unstressed etrl-1, however, was WTlike (Fig. 1b) suggesting that mechanisms other than the 

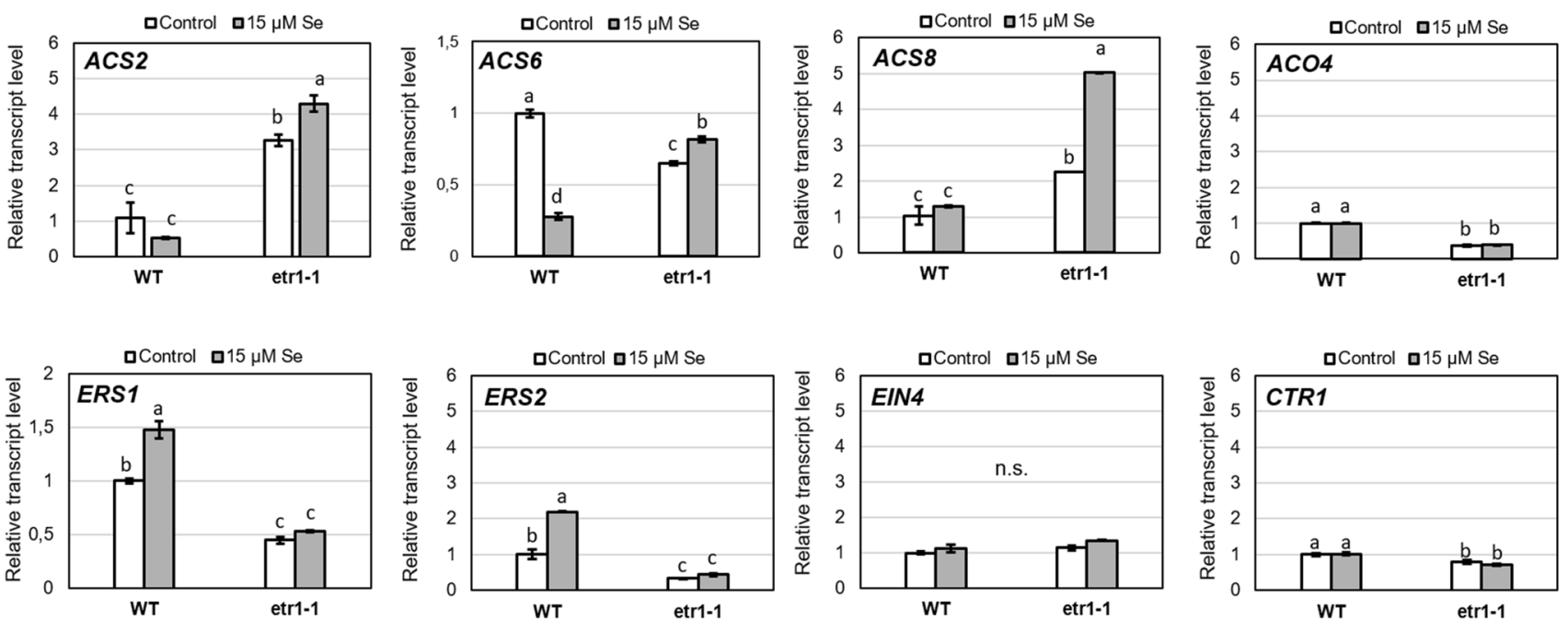

Fig. 2 Relative expression of selected ET-related genes in 7-day-old wild-type and etr1-1 Arabidopsis grown in the presence or absence of $15 \mu \mathrm{M}$ selenite. Different letters indicate significant differences according to Duncan's test $(n=2, P \leq 0.05)$. Data were normalized

using the A. thaliana actin2 and GAPDH2 genes as internal controls. The relative transcript level in WT control samples was arbitrarily considered to be 1 for each gene

expression of ET biosynthetic genes control endogenous ET levels in etrl-1 (e.g. posttranslational modifications of ACS activities, Wang et al. 2002).

Nitric oxide is known to be involved in LR development and interacts with ET in several processes of plant growth. As shown in Fig. 3, Se treatment resulted in 1.8-fold NO

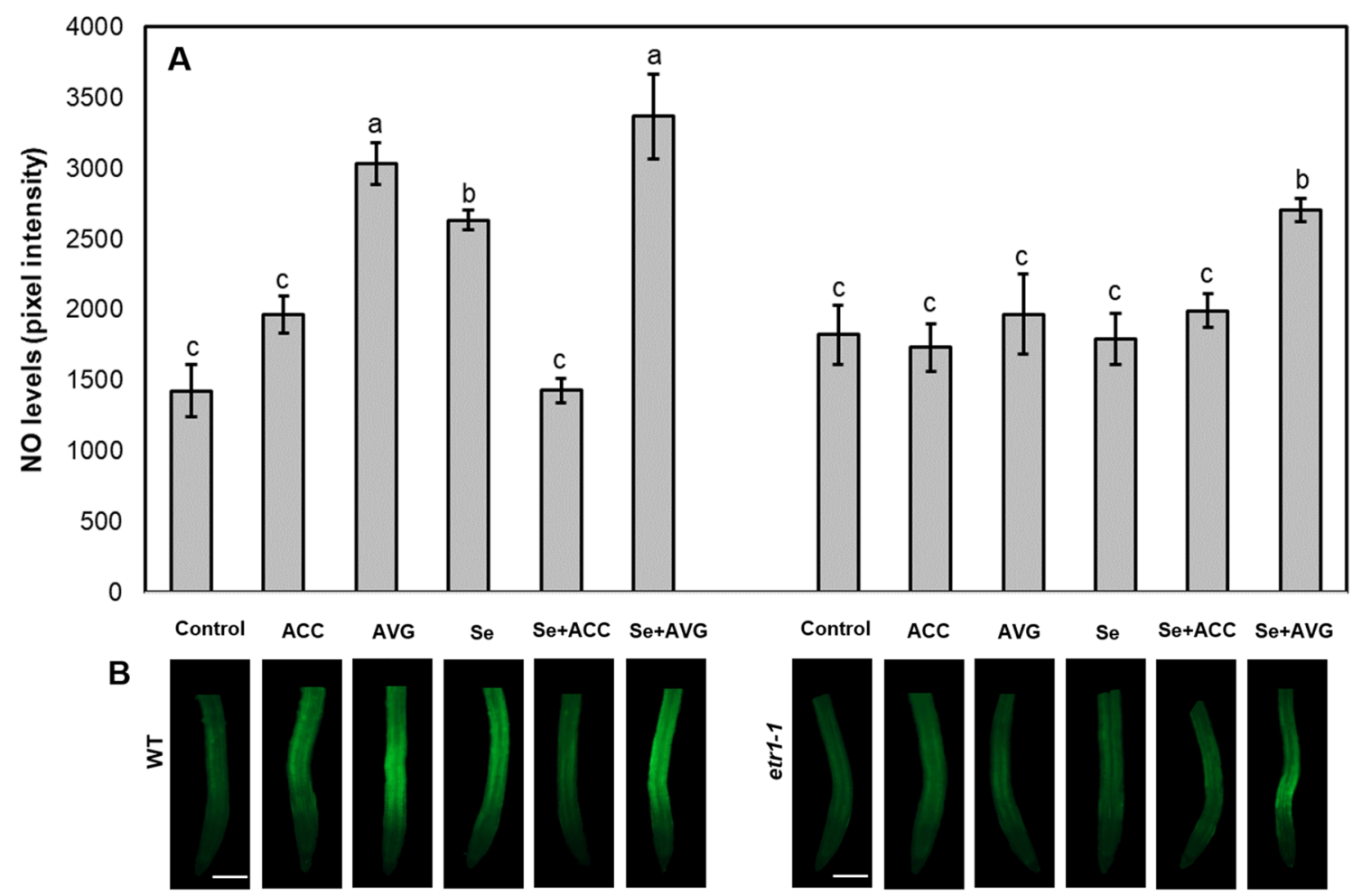

Fig. 3 a Nitric oxide levels (pixel intensity of DAF-FM) in the roots of 7-day-old wild-type and etr1-1 Arabidopsis grown in the presence or absence of $15 \mu \mathrm{M}$ selenite with or without $5 \mathrm{nM}$ ACC or $1.5 \mu \mathrm{M}$ AVG. Different letters indicate significant differences according to
Duncan's test $(n=10, P \leq 0.05)$. b Representative fluorescent microscopic images of DAF-FM-stained roots of 7-day-old wild-type and etrl-1 Arabidopsis. Bars $=500 \mu \mathrm{m}$ 
levels in WT roots (Fig. 3a), and the increment of NOdependent DAF-FM fluorescence was restricted to the transition zone of the primary root (Fig. 3b). In contrast, ET insensitive etrl-1 roots showed no Se-induced NO level increase which implies the possibility that functional ETR signalling is needed for Se-induced NO formation. The expressions of the examined NO-associated genes nitrate reductase 1 and $2(N R 1, N R 2)$, S-nitrosoglutathione reductase (GSNOR), nitrogen regulatory protein P-II homolog (GLB1), non-symbiotic hemoglobin 2 (GLB2) were not modified by Se in the WT and in etrl-1 only GLB2 was upregulated by Se (Fig S3). These results indicate that in Se-exposed Arabidopsis, the NO levels may not be regulated by the expression of the examined genes.

Based on the lack of Se-triggered NO increase in etrl1, we can suppose that NO levels can be controlled by ET levels in Se-stressed plants. The application of the ET biosynthetic inhibitor AVG resulted in the remarkable induction of NO levels with or without Se (Fig. 3). Similarly, an increased NO level was detected in etrl-1 treated with $\mathrm{Se}+\mathrm{AVG}$ compared to plants treated with Se alone (Fig. 3). The NO generating effect of ET inhibition suggests that elevated ET levels may prevent NO

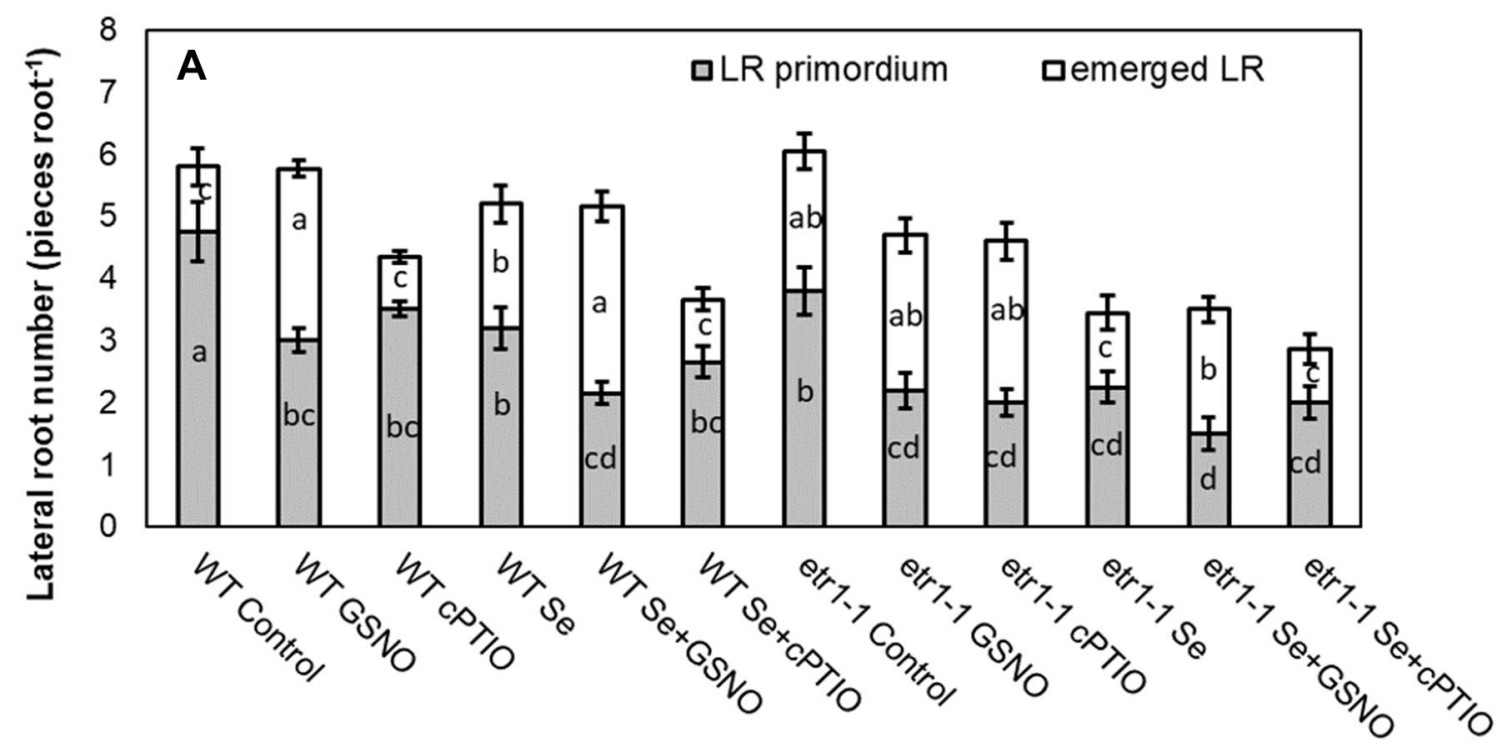

B
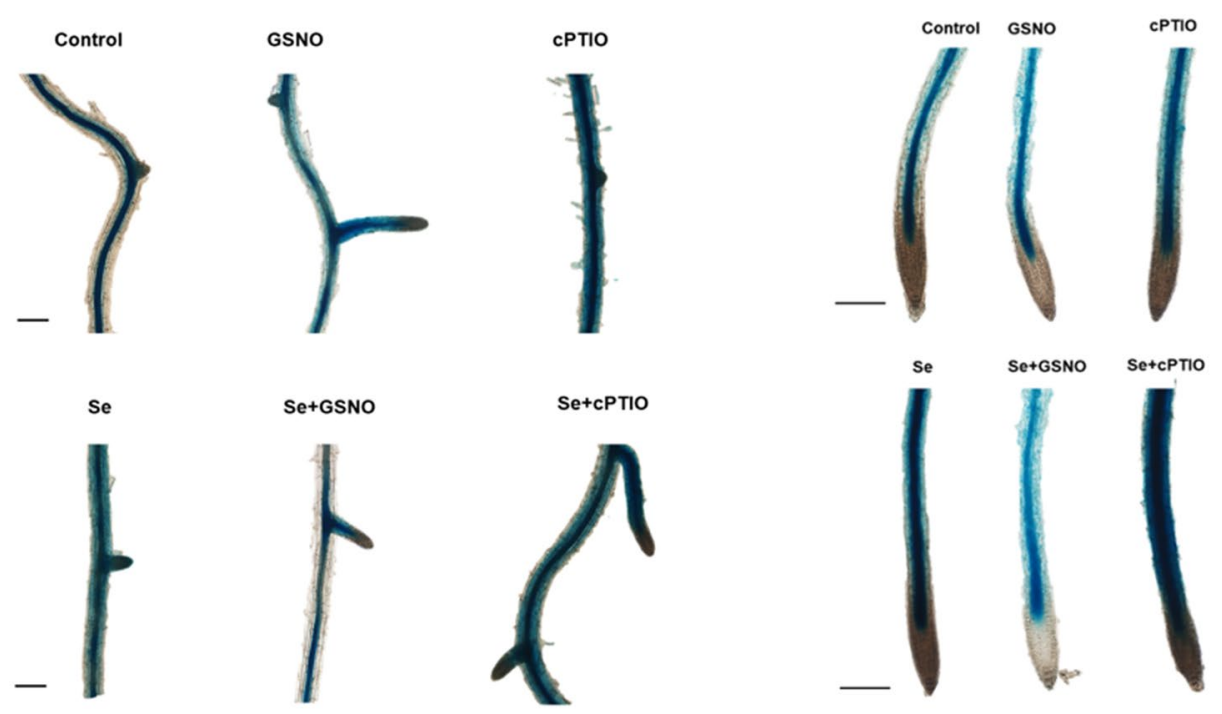

Fig. 4 a Number of lateral root (LR) primordia and emerged LRs in 7-day-old wild-type (WT) and etr1-1 Arabidopsis grown in the presence or absence of $15 \mu \mathrm{M}$ selenite with or without $250 \mu \mathrm{M}$ GSNO or $800 \mu \mathrm{M}$ cPTIO. Different letters indicate significant differences according to Duncan's test $(n=20, P \leq 0.05)$. b Primary roots and differentially developed LRs of X-Gluc-stained ACS8::GUS/GFP Arabidopsis grown on agar medium supplemented with 0 or $15 \mu \mathrm{M}$ selenite with or without $250 \mu \mathrm{M}$ GSNO or $800 \mu \mathrm{M}$ cPTIO. Bars $=500 \mu \mathrm{m}$ 
level increase in the root system of Se-exposed etrl-1. The mechanism by which ET negatively influences NO production remains to be elucidated.

The modification of endogenous NO levels in control and Se-stressed plants could answer the question of whether NO influences ET levels or not and can also clarify the role of NO in Se-induced LR outgrowth. Treatments with the NO donor GSNO resulted in intense LR emergence in control WT plants and a slighter inducing effect in Se-stressed plants (Fig. 4a). These effects could be reversed by the NO scavenger cPTIO but the rate of the effect was not statistically significant in every case. The root system of control etr $1-1$ proved to be NO insensitive, because neither GSNO nor cPTIO had a significant effect on LR emergence, but in the presence of Se, GSNO was able to notably increase $\mathrm{LR}_{\mathrm{em}}$ number and cPTIO had a slight inhibitory effect (Fig. 4a). Collectively, these data mean that the enhancement of endogenous NO levels in Se-treated WT and etrl-1 results in enhanced LR outgrowth which reflects the positive regulatory role of NO during Se-induced LR emergence. In addition to cPTIO inhibiting LR outgrowth it had a clear positive effect on $A C S:: G U S / G F P$ activity within the root system, whereas GSNO remarkably reduced the ET signal both in the PR and in the LRs (Fig. 4b) in accordance with previous studies reporting and explaining the suppressive effect of NO on ET synthesis (Eum et al. 2009; Cheng et al. 2009; Lindermayr et al. 2006; Abat and Deswal 2009; Tierney et al. 2005).

\section{Conclusion}

These results collectively indicate that in the Se-stressed root system, increased ET levels inhibit NO generation and NO negatively influences ET levels. It was shown for the first time that the antagonistic interplay between the two gasotransmitters in turn regulates the emergence of lateral roots in Arabidopsis under Se stress.

Acknowledgements Open access funding provided by University of Szeged (SZTE). This work was supported by the János Bolyai Research Scholarship of the Hungarian Academy of Sciences (Grant no. BO/00751/16/8) by the National Research, Development and Innovation Fund (Grant no. NKFI-6, K120383 and PD120962) and by the EU-funded Hungarian grant EFOP-3.6.116-2016-00008. Zs. K. was supported by UNKP-18-4 New National Excellence Program of the Ministry of Human Capacities. We thank É. Kapásné Török for excellent technical assistance.

Author Contributions ZSK conceived and designed research. GF, EH, ÁM, DO and PP performed experiments. ZSK wrote the paper.

\section{Compliance with Ethical Standards}

Conflict of interest The authors declare that they have no conflict of interest.

Open Access This article is distributed under the terms of the Creative Commons Attribution 4.0 International License (http://creativeco mmons.org/licenses/by/4.0/), which permits unrestricted use, distribution, and reproduction in any medium, provided you give appropriate credit to the original author(s) and the source, provide a link to the Creative Commons license, and indicate if changes were made.

\section{References}

Abat JK, Deswal R (2009) Differential modulation of S-nitrosoproteome of Brassica juncea by low temperature: change in S-nitrosylation of Rubisco is responsible for the inactivation of its carboxylase activity. Prot 9:4368-4380. https://doi.org/10.1002/ pmic. 200800985

Chang C, Kwok SF, Bleecker AB, Meyerowitz EM (1993) Arabidopsis ethylene-response gene ETR1: similarity of product to two-component regulators. Science 262:539-544. https://doi.org/10.1126/ science. 8211181

Chen Y, Mo HZ, Hu LB, Li YQ, Chen J, Jang LF (2014) The endogenous nitric oxide mediates selenium-induced phytotoxicity by promoting ROS generation in Brassica rapa. PLoS ONE 9(10):e110901. https://doi.org/10.1371/journal.pone.0110901

Cheng G, Yang E, Lu W, Jia Y, Jiang Y, Duan X (2009) Effect of nitric oxide on ethylene synthesis and softening of banana fruit slice during ripening. J Agric Food Chem 57:5799-5804. https://doi. org/10.1021/jf901173n

Dugardeyn J, Vandenbussche F, Van Der Straeten D (2008) To grow or not to grow: what can we learn on ethylene-gibberellin crosstalk by in silico gene expression analysis? J Exp Bot 59(1):1-16. https://doi.org/10.1093/jxb/erm349

Eum HL, Kim HB, Choi SB, Lee SK (2009) Regulation of ethylene biosynthesis by nitric oxide in tomato (Solanum lycopersicum L.) fruit harvested at different ripening stages. Eur Food Res Technol 228:331-338. https://doi.org/10.1007/s00217-008-0938-3

Feigl G, Kumar D, Lehotai N et al (2013) Physiological and morphological responses of the root system of Indian mustard (Brassica juncea L. Czern.) and rapeseed (Brassica napus L.) to copper stress. Ecotoxicol Environ Saf 94:179-189. https:// doi.org/10.1016/j.ecoenv.2013.04.029

Freschi L (2013) Nitric oxide and phytohormone interactions: current status and perspectives. Front Plant Sci 4:398. https://doi. org/10.3389/fpls.2013.00398

Gallé Á, Csiszár J, Secenji M et al (2009) Glutathione transferase activity and expression patterns during grain filling in flag leaves of wheat genotypes differing in drought tolerance: response to water deficit. J Plant Phys 166(17):1878-1891. https://doi.org/10.1016/j. jplph.2009.05.016

Ivanchenko MG, Muday GK, Dubrovsky JG (2008) Ethylene-auxin interactions regulate lateral root initiation and emergence in Arabidopsis thaliana. Plant J 55:335-347. https://doi.org/10.1111/ j.1365-313X.2008.03528.x

Kolbert Z (2016) Implication of nitric oxide (NO) in excess element-induced morphogenic response of the root system. Plant Physiol Biochem 101:149-161. https://doi.org/10.1016/j.plaph y.2016.02.003 
Kolbert Z, Lehotai N, Molnár Á, Feigl G (2016) “The roots" of selenium toxicity: A new concept. Plant Signal Behav 11:10 e1241935. https://doi.org/10.1080/15592324.2016.1241935

Kolbert Z, Molnár Á, Szőllősi R, Feigl G, Erdei L, Ördög A (2018) Nitro-oxidative stress correlates with Se tolerance of Astragalus species. Plant Cell Physiol 59:1827-1843. https://doi.org/10.1093/ pcp/pcy099

Lehotai N, Kolbert Z, Petô A et al (2012) Selenite-induced hormonal and signalling mechanisms during root growth of Arabidopsis thaliana L. J Exp Bot 63:5677-5687. https://doi.org/10.1093/jxb/ ers222

Lehotai N, Feigl G, Koós Á, Molnár Á, Ördög A, Petô A, Erdei L, Kolbert Z (2016) Nitric oxide-cytokinin interplay influences selenite sensitivity in Arabidopsis. Plant Cell Rep 35:2181-2195. https:// doi.org/10.1007/s00299-016-2028

Lindermayr C, Saalbach G, Bahnweg G, Durner J (2006) Differential inhibition of Arabidopsis methionine adenosyltransferases by protein $S$-nitrosylation. J Biol Chem 281:4285-4291. https://doi. org/10.1074/jbc.M511635200

Malamy JE, Benfey PN (1997) Organization and cell differentiation in lateral roots of Arabidopsis thaliana. Dev 124:33-44

Molnár Á, Feigl G, Trifán V, Ördög A, Szőllősi R, Erdei L, Kolbert Z (2018a) The intensity of tyrosine nitration is associated with selenite and selenate toxicity in Brassica juncea L. Ecotoxicol Environ Saf 147:93-101. https://doi.org/10.1016/j.ecoenv.2017.08.038

Molnár Á, Kolbert Z, Kéri K, Feigl G, Ördög A, Szőllősi R, Erdei L (2018b) Selenite-induced nitro-oxidative stress processes in Arabidopsis thaliana and Brassica juncea. Ecotoxicol Environ Saf 148:664-674. https://doi.org/10.1016/j.ecoenv.2017.11.035

Negi S, Ivanchenko MG, Muday GK (2008) Ethylene regulates lateral root formation and auxin transport in Arabidopsis thaliana. Plant J 55:175-187. https://doi.org/10.1111/j.1365-313X.2008.03495.x

Papdi C, Ábrahám E, Joseph MP, Popescu C, Koncz C, Szabados L (2008) Functional identification of Arabidopsis stress regulatory genes using the controlled cDNA overexpression system. Plant Physiol 147(2):528-542. https://doi.org/10.1104/pp.108.116897

Peng H-P, Lin T-Y, Wang N-N, Shih M-C (2005) Differential expression of genes encoding 1-aminocyclopropane-1-carboxylate synthase in Arabidopsis during hypoxia. Plant Mol Biol 58:15-25. https://doi.org/10.1007/s11103-005-3573-4

Poór P, Kovács J, Borbély P, Takács Z, Szepesi Á, Tari I (2015) Salt stress-induced production of reactive oxygen-and nitrogen species and cell death in the ethylene receptor mutant Never ripe and wild type tomato roots. Plant Physiol Biochem 97:313-322. https://doi. org/10.1016/j.plaphy.2015.10.021

Potters G, Pasternak TP, Guisez Y, Palme KJ, Jansen MAK (2007) Stress-induced morphogenic responses: growing out of trouble? Trend Plant Sci 12:98-105. https://doi.org/10.1016/j.tplan ts.2007.01.004

Schellingen K, Van Der Straten D, Vandenbussche F, Prinsen E, Remans T, Vangronsveld J, Cuypers A (2014) Cadmium-induced ethylene production and responses in Arabidopsis thaliana rely on ACS2 and ACS6 gene expression. BMC Plant Biol 14:214. https ://doi.org/10.1186/s12870-014-0214-6

Sors TG, Ellis DR, Salt DE (2005) Selenium uptake, translocation, assimilation and metabolic fate in plants. Photosynth Res 86:373389. https://doi.org/10.1007/s11120-005-5222-9

Tamaoki M, Freeman JL, Pilon-Smits EAH (2008) Cooperative ethylene and jasmonic acid signaling regulates selenite resistance in Arabidopsis. Plant Physiol 146:1219-1230. https://doi. org/10.1104/pp.107.110742

Tierney DL, Rocklin AM, Lipscomb JD, Que L, Hoffman BM (2005) ENDOR studies of the ligation and structure of the non-heme iron site in ACC oxidase. J Am Chem Soc 127:7005-7013. https://doi. org/10.1021/ja0500862

Tsuchisaka A, Theologis A (2004) Unique and overlapping expression patterns among the Arabidopsis 1-amino-cyclopropane-1-carboxylate synthase gene family members. Plant Physiol 136:29823000. https://doi.org/10.1104/pp.104.049999

Van Hoewyk D, Takahashi H, Inoue E, Hess A, Tamaoki M, PilonSmits EAH (2008) Transcriptome analyses give insight into selenium-stress responses and selenium tolerance mechanisms in Arabidopsis. Physiol Plant 132:236-253. https://doi.org/10.111 1/j.1399-3054.2007.01002.x

Wang KLC, Li H, Ecker JR (2002) Ethylene biosynthesis and signaling networks. Plant Cell. https://doi.org/10.1105/tpc.001768

Zhong S, Shi H, Xue C, Wei N, Guo H, Deng XW (2014) Ethylene-orchestrated circuitry coordinates a seedling's response to soil cover and etiolated growth. Proc Natl Acad Sci USA 111(11):3913-3920. https://doi.org/10.1073/pnas.1402491111

Publisher's Note Springer Nature remains neutral with regard to jurisdictional claims in published maps and institutional affiliations. 